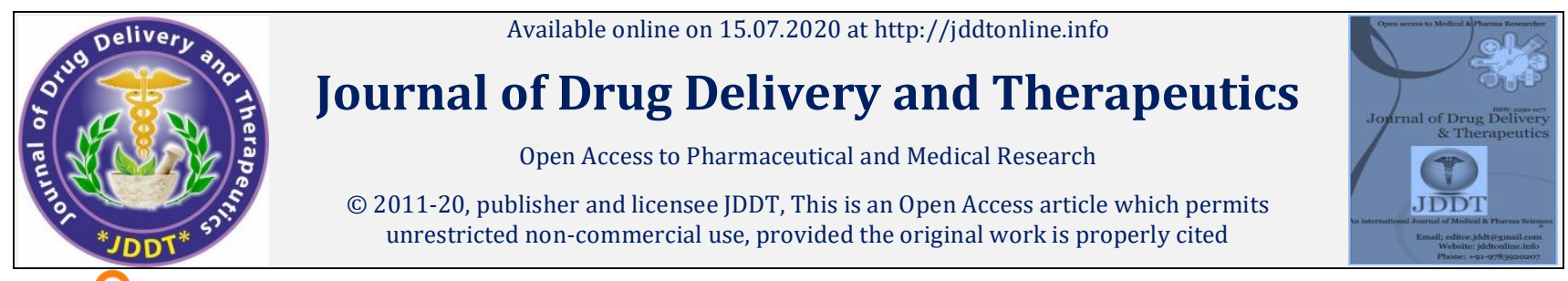

Open 1 Access

Short Communication

\title{
Triphala: A useful therapeutic supplement during COVID-19 pandemic
}

\section{Biplob Ozah*}

Laboratory Assistant, Department of Chemical Sciences, Tezpur University, 784028, Assam, India

\begin{abstract}
In this communication, efforts have been made to point out two different aspects: the clinical symptoms of COVID-19 and several therapeutic effects of 'Triphala'. The 'Triphala' have been acting as 'one formula therapy' since the time of the Ayurveda, and the COVID-19 is not an exception. The relationship between the pre- and post-symptom of COVID-19 and the therapeutic activity of 'Triphala' gives us a ray of hope to use Triphala as an anti-corona therapeutic supplement during the pandemic as well as in near future.
\end{abstract}

Keywords: COVID-19, Triphala, Ayurveda, Therapeutic activity

Article Info: Received 21 April 2020; Review Completed 16 June 2020; Accepted 24 June 2020; Available online 15 July 2020

Cite this article as:

Ozah B, Triphala: A useful therapeutic supplement during COVID-19 pandemic, Journal of Drug Delivery and Therapeutics. 2020; 10(4):219-220 http://dx.doi.org/10.22270/jddt.v10i4.4153

*Address for Correspondence:

Laboratory Assistant, Department of Chemical Sciences, Tezpur University, 784028, Assam, India

\section{INTRODUCTION}

\section{Concept of 'Tri-dosha' and 'Tridoshic Rasayana' in Ayurveda}

The knowledge of Ayurveda originated more than 5000 years ago in India and considered as the oldest healing science. Ayurveda means "The Science of Life". It identifies three basic types of energy principles or 'doshas' that are present in everyone and these are related to the basic biology of the body. These are - Vata, Kapha and Pitta. According to the Ayurvedic Philosophy, five universal great elements i.e., space, air, fire, water and earth collectively produced these three basic energy principles. ${ }^{1}$

Vata- made up of space and air; associated with movement. It governs breathing, blinking, muscle and tissue movement, pulsation of heart and all movements in the cytoplasm and cell membrane. ${ }^{1}$

Pitta- made up of fire and water; associated with body's metabolic system. It governs digestion, absorption, assimilation, nutrition, metabolism and body temperature. ${ }^{1}$

Kapha- made up of earth and water; associated with the body's structure. It supplies the water for all bodily parts and lubricates joints, moisturizes the skin and maintained immunity. 1

Misbalancing any one of 'dosha' creates abnormality, disorder and disease in human body. Triphala is classified as a 'Tridoshic Rasayana'. According to the writings of the great physician Charak in 'Charaka Samhita - a foundational text of Ayurveda', the 'Triphala' has been used in traditional ISSN: 2250-1177 medicine in India for over 1000 years. It promotes longevity and rejuvenation in patients of all compositions and ages. ${ }^{2}$

\section{Triphala (In Sanskrit; tri $=$ three and phala $=$ fruits)}

Triphala is a well-recognized and valued polyherbal medicine consisting of dried fruits of the three plant species Emblica officinalis (Amalaki), Terminalia bellerica (Bibhitaki) and Terminalia chebula (Haritaki). According to Charak, taking the Triphala Rasayana (Triphala with honey and ghee) daily has the potential to make a person live for one hundred years without old age and diseases. ${ }^{2}$

\section{Novel Corona Virus Disease (COVID-19)}

Coronavirus is one of the major pathogens that primarily target the human respiratory system. The symptoms of COVID-19 infection appear after an incubation period of 5 days (approximate). ${ }^{3}$ According to the World Health Organization, most people infected with the COVID-19 virus will experience mild to moderate respiratory illness and recover without special treatment. Older people who have cardiovascular history and cancer are more likely to develop serious illness. ${ }^{4}$ The period from the onset of COVID-19 symptoms to death ranged from 6 to 41 days (median of 14 days). ${ }^{3}$ Clinical features revealed by a chest CT scan presented as pneumonia, however, there were abnormal features such as RNAaemia, acute respiratory distress syndrome, acute cardiac injury and incidence of grand-glass opacities that led to death. ${ }^{3}$ At present, there is no specific antiviral drug/vaccine against COVID-19 infection for potential therapy in humans. Social distancing is the only solution to reduce transmission of COVID-19. 


\section{Home quarantining and its affect}

To prevent from the spread off COVID-19, most of the countries already have declared a complete lockdown. The governments appeal their citizens to follow the norms of social distancing. Home quarantining is the best measure to maintain complete social isolation. If one person didn't take part in any type of physical work/activity, then it may alter the bodily absorption and digestion mechanism. On the other hand, In India, most of the family has the gastrointestinal problem like gastric hyperacidity. The 'Work from Home' person may also suffer from the same due to less physical activity. As lock-down frontwards, the fear of COVID-19 also increases day-by-day and it directly elevated the level of stress of elder and weak persons. Absence of physical activity also makes a person more obese than earlier. In this situation, who already have has the history of high blood sugar, carcinogenesis, hypertension; smoking habit is under the highly susceptible group of COVID-19.3

\section{METHODS}

A search of the Ayurveda and PubMed database was conducted by referred author(s).2

\section{RESULTS AND DISCUSSION}

From the above discussion, we came to know about various disorders and conditions of quarantined, hospitalized and COVID-19 positive (after diagnosis) person. The supplementation of 'Triphala' as directed by physician may be helpful during this situation to cure themselves many conditions that occur due to lifestyle modifications during the pandemic as well as COVID-19 positive person. Various animal and human trial studies have validated a number of potential uses of 'Triphala'. Triphala have-

(a) Hypercholesteremic effects: It reduces total cholesterol, low-density lipoprotein, very low-density lipoprotein, and free fatty acid levels. ${ }^{2}$

(b) Anti-inflammatory effects: Triphala extract is significantly more effective than the non-steroidal antiinflammatory drug- indomethacin, in ameliorating arthritic and inflammatory effects. ${ }^{2}$

(c) Gastrointestinal effects: It reduces constipation, mucous, abdominal pain, hyperacidity, and flatulence while improving the frequency, yield, and consistency of stool. ${ }^{2}$

(d) Stress-reducing effects: It prevents noise-induced stress, protect against cold-induced stress and reverse stress-induced behavioral alterations and biochemical changes such as increased lipid peroxidation and corticosterone levels. ${ }^{2}$

(e) Antiobesogenic effects: It acts as therapeutic agent for weight loss and reduction of body fat. ${ }^{2}$

(f) Antidiabetic effects: It inhibits digestive enzymes and may decrease absorption of glucose through inhibition of glycolytic enzymes, thereby reducing blood glucose levels. It plays in inhibiting starch digestion and absorption, thereby decreasing postprandial hyperglycemia. It may also prevent glycation through promotion of lower blood glucose levels. ${ }^{2}$

(g) Antineoplastic effects: It exerts an antineoplastic effect on many cancer cell lines, including those of the breast, prostate, colon, and pancreas. It induces cytotoxicity in cancer cells, which showed increases in intracellular reactive oxygen species. $^{2}$

(h) Anti-immunosenescence effects: Immunosenescence refers to the gradual deterioration of the immune system. Triphala has antioxidantal activity and especially it prevents immunosenescence. ${ }^{2}$

(i) Immunomodulating effects: i.e., activating immune system. $^{2}$

(j) Analgesic effects: i.e., act as painkiller. ${ }^{2}$

(k) It increases the production of red blood cells and hemoglobin. ${ }^{2}$

(l) Bronchodilator effects: Bronchodilator is a substance that dilates the bronchi and bronchioles which decreases resistance in the respiratory airway and increases airflow to the lungs. It is administered for the treatment of breathing difficulties. Triphala act as bronchodilator. ${ }^{2}$

\section{CONCLUSION}

Triphala is a powerful polyherbal formula with numerous effective therapeutic uses. ${ }^{2}$ It helps in maintaining homeostasis as well as the prevention and treatment of various diseases. The current study is completely based on previous research and tries to link the Triphala with the symptom-prevention measures of COVID-19. Triphala supplement is prepared in Indian sub-continent locally at some households and by various pharmaceutical companies. This short communication is concluded with a hope to adapt the 'Tridoshic Rasayana' in every household and have further exploration of this topic in the preparation of medication for COVID-19.

\section{ACKNOWLEDGEMENT}

I express my cordial sense of appreciation and obligation to the authors (present in the reference) for their greatest research on Ayurveda, Thriphala and COVID-19 and give a ray of hope to fight against the global pandemic.

\section{Conflicts of Interest: None}

\section{REFERENCES}

1. Lad B, "Ayurveda: A Brief Introduction and Guide", The Ayurvedic Institute, 2006.

2. Peterson C T, Denniston K and Chopra D, "Therapeutic Uses of Triphala in Ayurvedic Medicine", The Journal of Alternative And Complementary Medicine, 2017; 23(8):607-614.

3. Rothan $\mathrm{H}$ A and Byrareddy S N, "The epidemiology and pathogenesis of coronavirus disease (COVID-19) outbreak", Journal of Autoimmunity, 2020, 109.

4. Coronavirus: Available at https://www.who.int/healthtopics/coronavirus\#tab=tab_1. Accessed 1 May 2020. 